\title{
Surface modification of Ti-6Al-4V alloys using triode plasma oxidation treatments
}

\author{
G. Cassar ${ }^{\text {a,* }}$, J.C. Avelar-Batista Wilson ${ }^{\text {b }}$, S. Banfield ${ }^{\mathrm{a}, \mathrm{b}}$, J. Housden ${ }^{\mathrm{b}}$, A. Matthews ${ }^{\mathrm{a}}$, A. Leyland ${ }^{\mathrm{a}}$ \\ a Department of Materials Science and Engineering, University of Sheffield, Sir Robert Hadfield Building, Mappin St., Sheffield S1 3JD, UK \\ b Tecvac Ltd, Buckingway Business Park, Swavesey, Cambridge CB24 4UG, UK
}

\section{A R T I C L E I N F O}

\section{Article history:}

Received 6 October 2011

Accepted in revised form 1 May 2012

Available online 9 May 2012

\section{Keywords:}

Triode plasma oxidation

Ti-6Al-4V

Wear

\begin{abstract}
A B S T R A C T
In this study, triode plasma oxidation (TPO) has been used to improve the tribological characteristics of Ti-6Al-4V. The effect of TPO on ball-on-plate reciprocating-sliding, impact, and micro-abrasion wear resistance of this alloy is investigated. Surface micro-profilometry, nano-/micro-indentation hardness testing, scratch-adhesion testing, scanning electron microscopy (SEM), atomic force microscopy (AFM), glancing-angle X-ray diffraction (GAXRD), and glow-discharge optical emission spectroscopy (GDOES) data is presented to corroborate the effects of the oxidation process. 'Traditional' thermal oxidation processes were used to benchmark this novel treatment. Following TPO treatment at $700{ }^{\circ} \mathrm{C}$ for only $4 \mathrm{~h}$, a hard (exceeding $11 \mathrm{GPa}$ ) and well-adhered oxide layer, composed of mixtures of the anatase and rutile polymorphs of $\mathrm{TiO}_{2}$, was formed at the surface of the Ti-alloy. This layer is accompanied by a much larger oxygen-solution strengthened zone which creates a gradual chemical and mechanical gradient from the hard oxide 'compound layer' into the ductile substrate core. The various wear testing methods employed revealed excellent wear resistance of the TPO-treated alloy-compared both to the untreated alloy and to conventional, thermally oxidised samples.
\end{abstract}

(c) 2012 Elsevier B.V. All rights reserved.

\section{Introduction}

Titanium alloys show attractive combinations of both mechanical and physical properties and have therefore found wide application in commercial engineering applications-particularly for the transport and biomedical sectors of industry. However, their wear performance is often very poor, restricting their use to non-tribological load-bearing systems. The nascent oxide film present on titanium alloy surfaces, although corrosion-resistant, is vulnerable to mechanical and tribological loading and therefore, up until a few years ago, forced oxidation of Ti alloys (to thicken and modify the nascent surface film) was not considered for the improvement of tribological characteristics. The primary reason for this is that the thick layers formed during such oxidative processes were unable to resist mechanical damage and susceptible to spall from the substrate under load. Spallation can result from stresses within the oxide layer, which progressively increase with oxide thickness [1]. Such stresses can be attributed to three principal effects:

(i) The large volume expansion of Ti upon its oxidation measured by the Pilling-Bedworth ratio (PBR), which in the case of (rutile) $\mathrm{TiO}_{2} / \mathrm{Ti}$ is $1.73[2,3]$ (for a value in excess of one, compressive stress will rapidly develop in the growing oxide scale-thus a high PBR value of 1.73 implies inherently large growth stresses in oxide layers on titanium and its alloys);

\footnotetext{
* Corresponding author. Tel.: + 3562340 2140; fax: + 35621343577. E-mail address: glenn.cassar@um.edu.mt (G. Cassar).
}

(ii) the high lattice mismatch between the tetragonal structure of the oxide and the underlying hexagonal/cubic metal [4];

(iii) the substantial difference in linear coefficients of thermal expansion [5], creating compressive and tensile stresses in the oxide compound layer and the metallic diffusion zone respectively, along the metal/oxide interface.

In recent years, numerous methods have been investigated, in attempts to produce thicker oxide layers intended for the enhancement of the tribological properties of Ti alloys. These techniques include anodising [6], ion implantation [7], dc-diode plasma oxidation [8], plasma electrolytic oxidation [9], reactive dc-sputtering [10], vacuum heat treatment [11], thermal oxidation (TO) [12,13], oxygen-boost diffusion [14-16] and palladium-treated thermal oxidation [17,18]. Different techniques have each proved capable of producing thick oxide layers resilient to both chemical and mechanical attack. However, thermal oxidation probably remains the leading technique for the treatment of titanium-since it readily produces thick, highly-crystalline rutile oxide films [18]. This process also has considerable commercial and environmental advantages, as it simply involves the heating of a component to a temperature between $450{ }^{\circ} \mathrm{C}$ and $900{ }^{\circ} \mathrm{C}$ in an oxygen-containing environment from, say, one hour up to many tens, or even hundreds of hours $[13,19,20]$.

Unfortunately, the formation of weakly-adhered oxide scales is still a particular concern. This very much depends on the process parameters chosen; particularly oxidation temperature, process duration and cooling rate. Oxidation temperatures above $700{ }^{\circ} \mathrm{C}$ can rapidly lead to oxide debonding because of the increased layer thickness which (as already 
described above) is associated with increased stress levels-but this can also be due to stratification of the oxide layer (together with increasing porosity) as the treatment time is lengthened [21]. Conversely, temperatures that are too low, say below around $500{ }^{\circ} \mathrm{C}$, do not provide the necessary activation energy for oxygen dissolution in the titanium lattice [13]. On the other hand, short treatment durations at higher temperatures may not produce a sufficiently thick oxide compound layer for an appreciable improvement in tribological properties [22].

Recently, Krishna et al. [20] successfully produced well-adhered thick (up to $\sim 100 \mu \mathrm{m}$ ) oxide layers, capable of providing low wear rates by avoiding the onset of large thermal stresses-using slow furnace cooling (and thereby lowering the instantaneous temperature gradient). Unfortunately, there is no conclusive evidence as to whether the thick oxide would debond under high Hertzian contact stresses or possible thermal shocking during service. An opposite approach in relation to the cooling rate was taken by other researchers, in order to promote good oxide adhesion. After oxidation treatment, Borgioli et al. [23] used a jet of air to rapidly cool the samples and thus enhance the oxide films' natural tendency to loosen from the surface-thereby exfoliating poorly adherent oxide layers. Similarly, Yan and Wang [24] quenched samples in water and lightly ground them with SiC to expose the underlying oxygen diffusion layer. In the latter case, the surface hardness was clearly increased by the presence of the diffusion zone; however, no evidence of improved tribological performance was shown. The wear performance of TO-treated Ti, as for other such diffusion treatments, is expected to be severely compromised once the hard, inert titanium-oxide compound layer is removed.

On the other hand, the body of work related to oxygen plasmas for titanium surface engineering applications is very small, with literature related specifically to the intensified plasma diffusion treatments used in the present work (other than for plasma nitriding) being practically absent. Leng et al. [8] used dc-plasma oxidation to synthesise oxide layers to improve the biocompatibility and wear resistance of commercially pure titanium. Januszewicz and Siniarski [25], on the other hand, used an $\mathrm{Ar}+\mathrm{O}_{2}$ dc-plasma glow discharge during the diffusion stage, to enhance oxygen diffusion kinetics; however, the use of a diode plasma resulted in little or no increase in the hardened layer thickness compared to thermal oxidation. Clearly, there is still ample scope for further work in order to permit the use of oxidation processes for engineering applications of titanium that involve tribological surface contacts.

Recent publications [26-29] by the authors of this paper have shown that low-pressure triode plasma nitriding is capable of providing significant improvements in the tribological properties of Ti-6Al-4V-and it appears that triode plasma oxidation (TPO) may also be a suitable surface engineering technique for titanium [30]. In the research reported here, TPO treatments are used to generate a well adhered oxide layer on Ti$6 \mathrm{Al}-4 \mathrm{~V}$ alloy underneath which an oxygen-strengthened diffusion zone provides improved load-support. In particular, the tribological response of the treated Ti-alloy samples and the adhesion strength of titanium-oxide compound layers generated by TPO are assessed. These are then compared to the characteristics of samples treated using 'traditional' thermal oxidation treatments-thereby highlighting the benefits of using an intensified oxygen plasma.

\section{Experimental details}

The notional chemical composition of the Ti-6Al-4V alloy used in this work is $6.01 \mathrm{wt} . \% \mathrm{Al}, 4.08 \mathrm{wt} . \% \mathrm{~V}$, balance Ti. The test coupons had a core hardness of $375 \pm 10 \mathrm{HK}_{0.025}$ and were polished to a mirror finish, with a measured surface roughness average $\left(R_{a}\right)$ of $0.03 \pm 0.01 \mu \mathrm{m}$.

The base material was diffusion-treated by triode plasma oxidation in a modified Tecvac IP70L commercial PVD coating system, using a low-pressure dc-triode configuration [31,32] and additional radiative heating. Triode plasma oxidation was carried out at $600{ }^{\circ} \mathrm{C}$ and $700{ }^{\circ} \mathrm{C}$ in mixtures of argon and oxygen, at a total gas pressure of $0.4 \mathrm{~Pa}$ and at a cathode voltage of $-200 \mathrm{~V}$. The process duration varied between
2 and 8 h. Preliminary TPO trials were performed in order to assess the effect of varying $\mathrm{Ar}: \mathrm{O}_{2}$ pressure ratios on oxide layer growth kinetics, morphology and surface topography. All other treatments were then held at a fixed (optimal) $30: 70 \mathrm{Ar}: \mathrm{O}_{2}$ partial pressure ratio and at $700{ }^{\circ} \mathrm{C}$.

Thermally oxidised samples were created (for comparison to TPO) at $700{ }^{\circ} \mathrm{C}$, inside a heated vacuum chamber containing oxygen at a pressure of around $30 \mathrm{~Pa}$ for either 4 or $10 \mathrm{~h}$. The two thermal oxidation processes were planned such that the first TO sample would be of equal duration to a 4 hour TPO process, whilst the second TO sample was held for $10 \mathrm{~h}$, such that the resultant oxide compound layer thickness (and hardness-depth profile) was comparable to that achieved in a 4 hour TPO process (as will be shown later, in Section 3).

\subsection{Characterisation}

Glancing-angle X-ray diffraction (GAXRD) studies were performed using a Siemens D5000 diffractometer ( $\mathrm{Cu} K_{\alpha}$ radiation) operated in Seeman-Bohlin geometry at a glancing angle of $2^{\circ}$ with a step size of $0.02^{\circ}$, and a step time of $5 \mathrm{~s}$. The applied tube acceleration voltage and current were $40 \mathrm{kV}$ and $30 \mathrm{~mA}$ respectively.

Knoop hardness micro-indentation measurements were performed with a Mitutoyo HM-01 microhardness tester, at indentation loads ranging from 25 to $500 \mathrm{gf}(1 \mathrm{gf}=9.81 \mathrm{mN}$ ); a dwell time of $20 \mathrm{~s}$ was used. Surface nano-indentation measurements were performed using a Hysitron Inc. Triboscope ${ }^{\mathrm{TM}}$ instrument, equipped with a Berkovich triangular-pyramidal diamond indenter. To provide mean (and standard error) values of hardness and modulus, fifteen indentations were made for each sample, with a maximum load of $\sim 5 \mathrm{mN}$ applied.

Detailed surface topographical information was obtained using a Digital Instruments Multimode Nanoscope IV atomic force microscope (AFM) fitted with rectangular $\mathrm{Si}_{3} \mathrm{~N}_{4}$ (Olympus Co.) cantilevers which had been previously gold coated on both sides. The cantilever had a nominal spring constant of $0.08 \mathrm{~N} / \mathrm{m}$. The instrument was operated in contact mode, at a frequency of $1 \mathrm{~Hz}$. The applied load during imaging was approximately $5 \mathrm{nN}$.

Glow-discharge optical emission spectroscopy (GDOES) measurements were made in Ar plasma using a Jobin Yvon (Horiba) rf GD-Profiler. The instrument was equipped with a copper anode $(4 \mathrm{~mm}$ diameter) glow-discharge source and operated using a $650 \mathrm{~Pa}$ Ar pressure and $30 \mathrm{~W}$ rf power. For each sample, the composition depth profiles extended through the surface layer into the bulk Ti-alloy. Subsequently, the depth of each scar was measured using surface micro-profilometry. In turn, this allowed for the quantification of sputter rates-and thus plotting of concentration-depth profiles.

\subsection{Scratch testing}

Scratch adhesion measurements were also necessary, to determine whether the triode plasma process improved the structural integrity and resistance of the oxide layer to delamination. Irrespective of the hardness-depth profile achievable through TPO processing, the practical use of such an oxidation treatment could still be severely limited by concerns related to the weakly adherent oxide scale $[20,23,24]$.

A commercial VTT scratch tester was also used to assess the oxide layer adhesion strength and measure the sample surface roughness. For scratch testing, a loading rate of $10 \mathrm{~N} / \mathrm{mm}$ was used and the sample was traversed at a speed of $10 \mathrm{~mm} / \mathrm{min}$. The load corresponding to complete spalling of this layer from the centre of the scratch track was determined by observing the damage events from a set of three scratches on each sample using an optical microscope.

\subsection{Wear testing}

Linear reciprocating ball-on-plate wear tests, described in the relevant ASTM standard G133-5 [33], were performed using a low-frequency reciprocating tribometer. A normal load of $4 \pm 0.1 \mathrm{~N}$ or $13.5 \pm 0.1 \mathrm{~N}$ 
was applied to a stationary WC-Co ( 5 to 7 wt.\% Co) ball of diameter $10 \mathrm{~mm}$. The ball-on-plate machine was set to run at $5 \mathrm{~Hz}$ with an amplitude of $10 \mathrm{~mm}$-and without lubrication. After the wear tests, surface profilometry was performed using a Veeco Dektak 150 stylus profilometer having a traversing resolution better than $0.05 \mu \mathrm{m}$ and a vertical resolution less than $0.01 \mu \mathrm{m}$; this allowed wear scar volume measurements to be made.

Ball-on-plate impact testing [34] was used to evaluate the resistance of the treated surfaces to dynamic loading. The head of the impact tester used in this work held a WC-Co ball of $6 \mathrm{~mm}$ diameter and this holding assembly was rapidly moved upwards and downwards, each time impinging on the sample surface. The measured impact force was continuously monitored and maintained constant for the test duration. The impact frequency was set at $8 \mathrm{~Hz}$. Each sample was subjected to a range of loading cycles from $10^{3}$ cycles up to a maximum of $250 \times 10^{3}$ cycles at a normal load of $400 \mathrm{~N}$; selected samples were also tested at a higher impact load of $500 \mathrm{~N}$ for $100 \times 10^{3}$ cycles. Following impact testing, crater volumes were measured using surface profilometry.

Micro-abrasion testing was performed using a commercially available (Plint TE-66) micro-scale abrasion tester; preconditioned bearing steel balls (100Cr6) were used as the counterface. The abrasive slurry, which was agitated continuously by means of a laboratory magnetic stirrer, was dripped onto the top of the rotating ball approximately every $5 \mathrm{~s}$ throughout the test. Between each test the ball was axially rotated slightly, such that no two tests used precisely the same circumferential band. The experimental conditions used are presented in Table 1.

Finally, 3D surface maps, generated from very accurate profilometry measurements, and Vision ${ }^{\circledR}$ 3D analysis software, were used to determine the wear scar volumes.

\section{Results and discussion}

Fig. 1 shows representative X-ray diffraction patterns for TPO-treated Ti-6Al-4V samples and for a thermally oxidised sample. Glancing-angle XRD patterns of TPO treatments, performed at $700{ }^{\circ} \mathrm{C}$ for 4 and $8 \mathrm{~h}$, show that the scale visible on the surface of the alloy is chiefly composed of mixtures of the anatase (ICDD file \#78-2486/21-1272) and rutile (ICDD file \#87-0920) polymorphs of $\mathrm{TiO}_{2}$.

An increase in the intensity of the titanium oxide peaks seems to be the predominant effect observed for the surface and near-surface composition-due to an increased TPO process duration. This higher peak intensity is likely to be as a consequence of the increase in oxide compound layer thickness with treatment time, as its contribution to the diffracted signal becomes higher. In fact, the measured oxide layer thicknesses were 1.88 and $3.05 \pm 0.1 \mu \mathrm{m}$, respectively, following TPO treatments of 4 and $8 \mathrm{~h}$. Previous experiments by the authors, involving different oxygen to argon partial pressure ratios, showed a similar (mixed) compound layer phase composition down to 30\% oxygen partial pressure (balanced by Ar), below which little or no anatase phase can be detected [30]. Conversely, the compound layer depth is

Table 1

Test conditions used for micro-abrasion tests.

\begin{tabular}{ll}
\hline Normal force $(\mathrm{N})$ & 0.1 \\
Ball rotational speed $(\mathrm{rpm})$ & $\sim 76.4$ \\
Tangential sliding velocity $(\mathrm{m} / \mathrm{s})$ & 0.1 \\
Abrasive material & $\mathrm{SiC}-$ Grade P1200 (Logitech Ltd., UK) \\
Slurry concentration $(\mathrm{g} / \mathrm{ml})$ & 0.8 \\
Volume fraction & 0.24 \\
Mean particle size $(\mu \mathrm{m})$ & $3.1($ St. Dev. $=2.7)$ \\
Abrasive carrier & Distilled Water \\
Ball diameter $(\mathrm{mm})$ & 25 \\
Ball material & Bearing steel $($ SAE52100) \\
Ball hardness (GPa) & 8.5 \\
No. of ball revolutions (revs) & $10,35,50,100,300,500,800$ \\
\hline
\end{tabular}

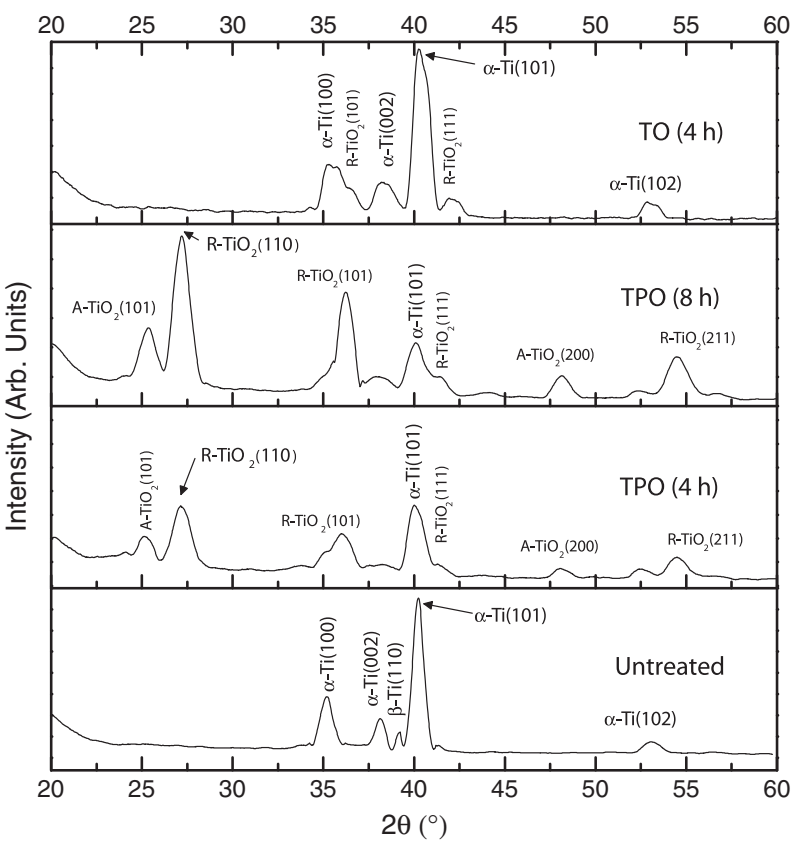

Fig. 1. GA-XRD ( $2^{\circ}$ angle of incidence) diffractograms of thermally oxidised, plasma oxidised (and untreated, for comparison) Ti-6Al-4V samples (A: Anatase, R: Rutile for $\mathrm{TiO}_{2}$ ). Both treatment types were carried out at $700{ }^{\circ} \mathrm{C}$; a $30: 70 \mathrm{Ar}: \mathrm{O}_{2}$ partial pressure ratio was used for TPO, whilst only $\mathrm{O}_{2}$ gas was used for TO.

significantly affected by oxygen content in the treatment plasma, with thickness increasing by approximately $0.3 \mu \mathrm{m}$ for every $10 \%$ increment in oxygen partial pressure between 10 and 70\%. Furthermore, when comparing TPO-treated surfaces to the unoxidised state, the $\alpha$-Ti peaks were shifted slightly to lower angles of $2 \theta$ upon oxidation, which shows that the dissolution of oxygen within the diffusion zone has expanded the Ti-metal lattice.

The XRD pattern for the $4 \mathrm{~h}$ TO treatment (also shown in Fig. 1) demonstrates some clear distinctions when compared to a sample treated with plasma assistance for the same duration. The pattern shows a predominant $\alpha$-Ti peak practically identical in intensity to the untreated samples, with two minor rutile oxide peaks also emerging. Clearly, thermal oxidation is much less efficient in oxide compound layer generation compared to the triode plasma treatments being investigated here. Indeed, the depth of the oxide layer produced in the TO-treated Ti-6Al-4V sample was only $0.42 \pm 0.1 \mu \mathrm{m}$ after $4 \mathrm{~h}$ i.e. an equivalent TPO-treatment provides a 3- to 4-fold increase in compound layer thickness. For plasma-assisted diffusion processes, the energetic species not only create lattice defects which accelerate diffusion but also activate the surface, thereby enhancing oxide formation. Such an increase in oxide layer thickness when oxidation is performed in the presence of plasma has also been demonstrated in [25]; however, for TPO processed samples no complex oxides $\left(\mathrm{Ti}_{\mathrm{x}} \mathrm{O}_{\mathrm{y}}\right)$ were identified.

Similar to what has already been discussed in a previous publication [26] in relation to nitriding treatments, this oxidation process also leads to a measurable degree of surface roughening. As in the case of nitrogen diffusion, an increase in surface roughness is observed for oxidised samples with increasing process temperature; however, for TPO processes a similar increase in roughness also occurs with increasing oxygen content in the plasma. At low oxygen partial pressures the surface of TPO-treated Ti-6Al-4V has an 'etched' appearance-and the surface oxide layers clearly replicate the substrate 'mill-annealed' microstructure, as can be seen in Fig. 2a and b. The AFM image in Fig. 2b shows regions of shallower oxide compound layer (darker in colour), located at the substrate material grain boundaries. It appears that oxygen inward diffusion at the grain boundaries is more rapid and therefore compound layer formation in these regions is slower. This can be attributed both to the well-known fact that grain boundary diffusion is in general much 
more rapid than in the crystal lattice-and also to retained $\beta$ phase along these boundaries.

As the oxygen content in the surface increases, its potent $\alpha$-stabilising effect transforms any retained $\beta$ phase into $\alpha$-thereby establishing a more uniform diffusion coefficient across the whole surface. Also, at higher oxygen partial pressures, supersaturation of the entire alloy surface is quicker-and therefore the oxide layer grows more rapidly and uniformly, leaving no trace of the parent microstructure (Fig. 2c and e). For a $4 \mathrm{~h}$ treatment, the oxide layer depth increases from $\sim 0.3 \mu \mathrm{m}$ at $10 \% \mathrm{O}_{2}$ to $\sim 1.9 \mu \mathrm{m}$ at $70 \% \mathrm{O}_{2}$ (Fig. $2 \mathrm{~d}$ and f); thus higher concentrations of $\mathrm{O}_{2}$ also result in a considerable increase in surface roughness (Fig. 3). However, contrary to previously reported work on thermally-generated oxide layers [23], our imaging and profilometry of TPO-treated Ti-alloy showed no visible porosity (which is often associated with thermal oxides) and therefore the use of intensified plasma in this work was expected to improve the density and overall quality of oxide formed. In fact, in the following sections the improved oxide quality will be directly correlated to its better adherence, making this oxidation process capable of being used as a 'stand-alone' wear resistant treatment for Ti under low-to-medium contact loads. The excellent oxide layer cohesion and increased thickness-together with acceptably low surface roughening-suggest that a constant 30:70 Ar: $\mathrm{O}_{2}$ partial pressure ratio can be employed for any TPO treatment process.

Following a 4 hour treatment process at a temperature of $700{ }^{\circ} \mathrm{C}$, a significant solid-solution strengthened case of up to $70 \mu \mathrm{m}$ in depth forms below the hard $\left(\sim 1200 \mathrm{HK}_{0.025}\right)$ surface oxide layer. In the case of oxidative processes, the generation of a thick compound layer does not inhibit the diffusion of oxygen through the underlying lattice, since the diffusion coefficient for oxygen in rutile $\mathrm{TiO}_{2}$ is about 50 times higher than in $\mathrm{Ti}(\mathrm{O})$ at the same temperature [35]. $\mathrm{TiO}_{2}$ is known to have an oxygen-deficient structure that produces oxygen ion vacancies, which in turn allows the passage of oxygen (by anion-vacancy diffusion) through the rutile lattice [5]. The GDOES profile of a TPO-treated sample in Fig. 4 shows the extent of oxygen penetration in the Ti lattice and also that the $\mathrm{Al}$ and $\mathrm{V}$ present in the substrate alloy are displaced from approximately the first $7 \mu \mathrm{m}$ of the surface. This may be particularly beneficial if the treated material is intended for implants-where

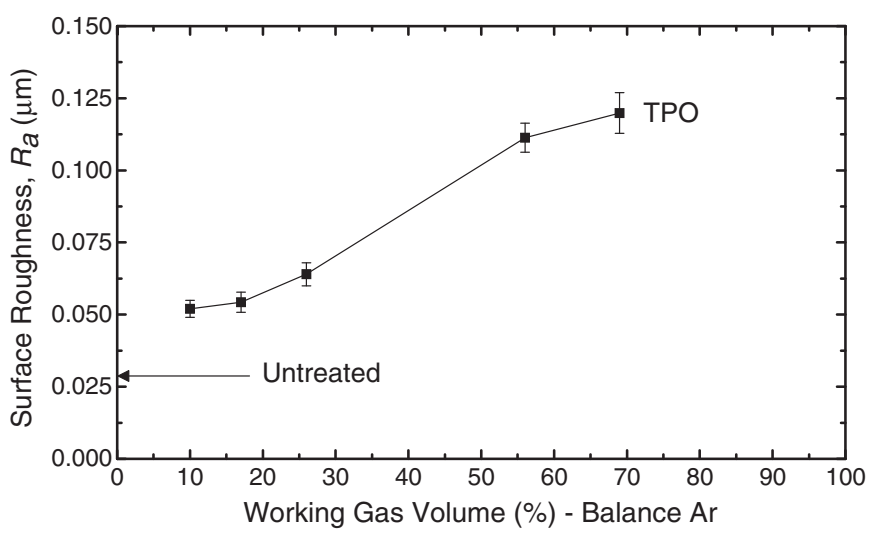

Fig. 3. Variation in $R_{a}$ with increasing working gas $\left(\mathrm{O}_{2}\right)$ content for a 4 hour TPO-treated Ti-6Al-4V.

good biocompatibility (with strong osseointegration) and low cytotoxicity are indispensable attributes. Although Ti-6Al-4V has been widely used as an implant material, some studies report that the release of $\mathrm{Al}$ and $\mathrm{V}$ ions may cause long-term health problems [36,37].

Fig. 5 shows how TPO surface hardness profiles evolve as the process duration increases. Two signs of the improved load-support provided by the deeper hardened case can be observed: (i) high hardness values maintained at relatively large indentation loads and (ii) a gradual drop in hardness value as the load is increased. The strengthened oxygen diffusion layer formed consists predominantly of $\alpha$-Ti grains stabilised by the increased $\mathrm{O}$ concentration. The dissolved oxygen increases preferentially the lattice parameter $c$, in the (oxygen-stabilised) $\alpha$-hcp crystal structure, whilst having a limited effect on $a$ [38]. This results in a net increase in the $c / a$ ratio accompanied by anisotropic distortion of the hcp lattice, reducing the number of active slip systems and hindering dislocation cross-slip which, as a consequence, increases the hardness of the Ti alloy [39].

An interesting observation can be made when comparing surface hardness data for TPO-treated samples and a sample treated with an equivalent thermal oxidation process carried out for $4 \mathrm{~h}$ at $700{ }^{\circ} \mathrm{C}$. In
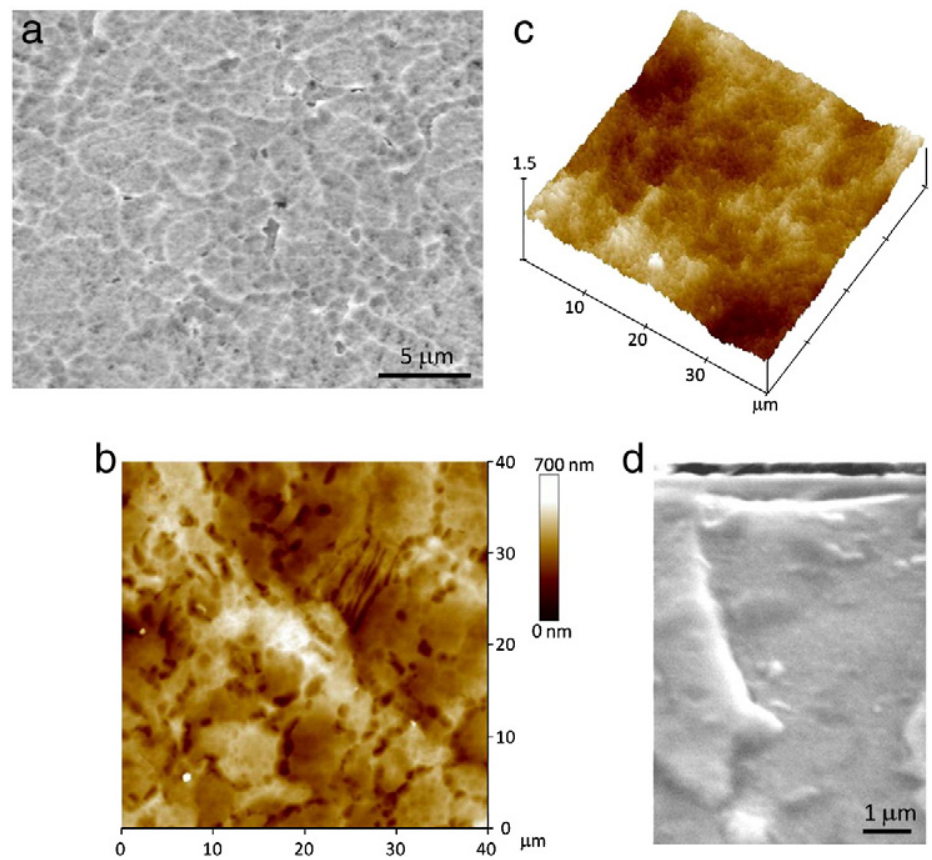
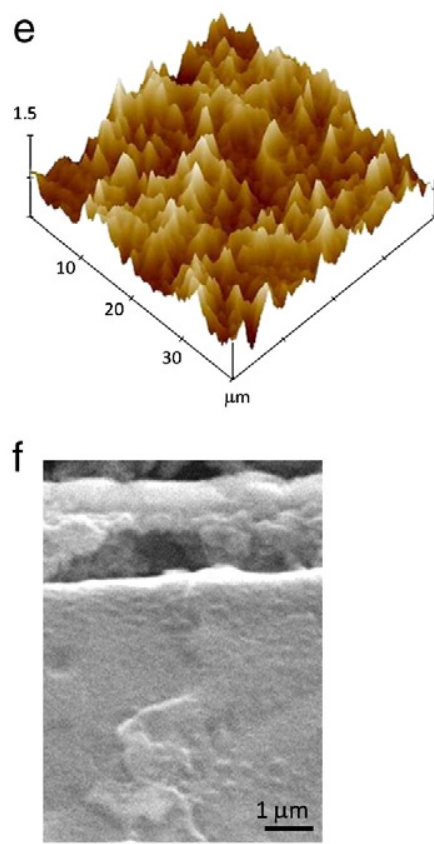

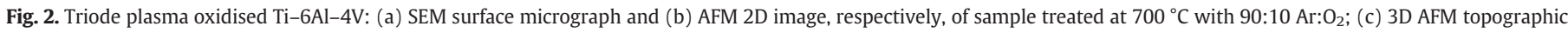

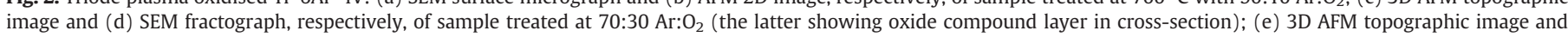
(f) SEM fractograph, respectively, of sample treated at 30:70 Ar: $\mathrm{O}_{2}$ (the latter showing oxide compound layer in cross-section). 


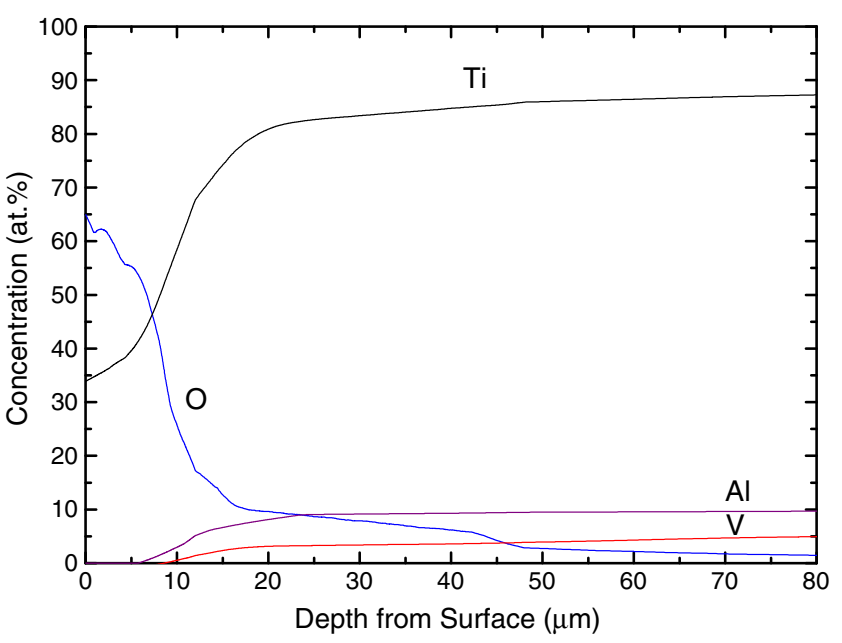

Fig. 4. GDOES composition-depth profile of TPO-treated Ti-6Al-4V. The sample was treated for $4 \mathrm{~h}$ at $700{ }^{\circ} \mathrm{C}$ using $30: 70 \mathrm{Ar}: \mathrm{O}_{2}$ partial pressure ratio.

agreement with previous work $[25,40,41]$, the TO treatment regime was found to be less efficient in hardening titanium compared to a plasmaassisted process. The triode plasma treatment used in this work is likely to accentuate further this discrepancy as the intensified plasma process is able to increase the generation of point defects compared to diode plasmas used elsewhere. In fact, the degree of surface hardening obtained following the TPO treatment shows that the use of a plasma gaseous environment more than doubles the efficacy of the oxidation process i.e. a $2 \mathrm{~h}$ TPO process is slightly superior to a $4 \mathrm{~h}$ TO process in terms of diffusion-zone hardening.

\subsection{Scratch testing}

Fig. 6 shows scratch test critical spalling load $\left(L_{C 3}\right)$ values corresponding to the complete removal of the TO- and TPO-treatment compound layers. The data provides clear evidence of the poor adhesion of oxide layers generated by thermal oxidation processes. The thin $(\sim 0.42 \mu \mathrm{m})$ oxide compound layer produced after a 4 hour thermal oxidation process proved to have a modest spalling load value of around $27.1 \mathrm{~N}$ whilst by comparison the thicker oxide layer $(\sim 1.94 \mu \mathrm{m})$ formed after $10 \mathrm{~h}$ exhibited extremely poor adhesion and is completely removed

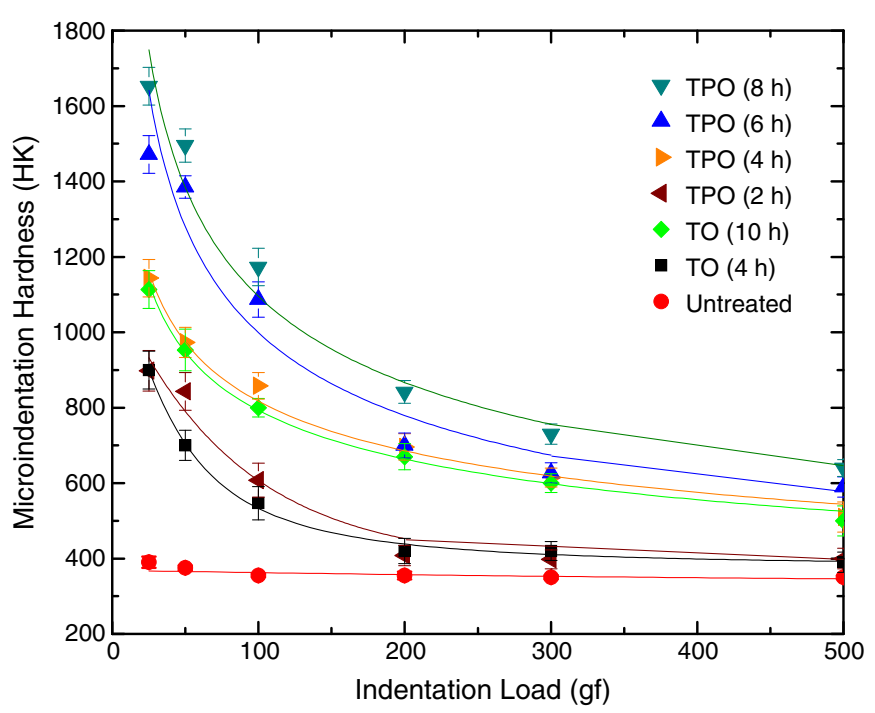

Fig. 5. Knoop surface microindentation hardness measurements of triode plasma oxidised and thermally oxidised Ti-6Al-4V. TPO samples were treated at $700{ }^{\circ} \mathrm{C}$ for 2 to $8 \mathrm{~h}$ using $30: 70 \mathrm{Ar}: \mathrm{O}_{2}$ partial pressure ratio, whilst the TO samples were treated at $700{ }^{\circ} \mathrm{C}$ for 4 and $10 \mathrm{~h}$ only $\mathrm{O}_{2}$ gas.

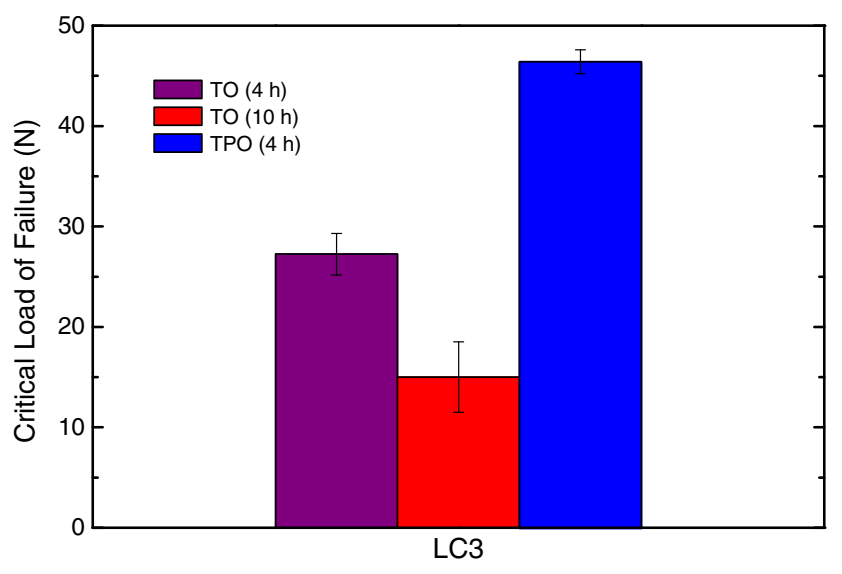

Fig. 6. Critical loads for spalling of oxide layer of TO and TPO samples. The oxide layer thicknesses were $0.42,1.94$, and $1.88 \mu \mathrm{m}$ for TO $(4 \mathrm{~h}, 10 \mathrm{~h})$ and TPO ( $4 \mathrm{~h})$ samples, respectively.

almost instantaneously. Thus, the (anticipated) rapid reduction in adhesion strength of thermal oxidation compound layers as their thickness increases is immediately apparent. Also, the deep hardened case below the oxide layer produced in extended thermal oxidation treatments provides no improvement in adherence. The reduction in adhesion compared to a $4 \mathrm{~h}$ TPO process, having both similar hardness-depth profile and compound layer thickness to that resulting following a $10 \mathrm{~h}$ TO process, indicates that the oxide layer structure and properties are critical to tribological behaviour. Another clear indication of the poor results obtained by TO treatment is visible in the SEM images shown in Fig. 7. Fig. 7a and c shows that brittle tensile cracks form in the TO compound layer at the very beginning of the scratch test; i.e. with the application of a $5 \mathrm{~N}$ pre-load. Conversely, for TPO compound layers no cracking is observed for a considerable distance along the initial scratch track profile.

The presence of microstructural defects in the TO compound layer, particularly after a longer treatment-together with rapid cooling from the processing temperature-may cause either immediate cracking, or residual tensile stress which adds to the stresses applied by the indenter during scratching. Conversely, the $4 \mathrm{~h}$ TPO process yields an oxide layer which is more compact and has less structural defects. None of the TPO variants produced in this work showed signs of compound layer exfoliation, whereas thermally-grown oxide scales appeared generally to be more stratified and 'flaky' when the process duration was extended to obtain comparable compound layer thicknesses. Nanoindentation also provides further evidence of the inferior characteristics of TO-treated samples. The surface nanoindentation hardness of $4 \mathrm{~h}$ TPO-treated and a $10 \mathrm{~h}$ TO-treated samples was measured to be $11.2 \mathrm{GPa}$ and $8.1 \mathrm{GPa}$, respectively. Considering that (i) the depth of penetration of the indenter was below $100 \mathrm{~nm}$ in both cases and (ii) the surface was chemically very similar, it appears that oxide layers produced by the TO process contain defects which (through microfracture) reduce the measured hardness.

The scratch load needed to spall a TPO oxide layer is in fact higher than that measured for a TiN ceramic coating of an equivalent thickness (when deposited on an untreated Ti-6Al-4V substrate) and is also comparable to that of TiN when deposited onto a nitrogen pre-treated surface having an equivalent hardened case depth [27]. Firstly, particularly in the early stages of oxide formation, the continuous bombardment of high energy species during the triode plasma oxidation process can create an improved transition of the oxide compound layer formation from the underlying oxygen-stabilised hcp $\alpha$-Ti material. This reduces the stresses generated during oxide film growth-thereby improving compound layer adhesion. Furthermore, the bombardment by ions of high kinetic energy is also capable of improving the physical characteristics of the growing oxide film, eliminating layer stratification. Secondly, the degree of substrate hardening and resulting load-support provided to the oxide layer by the underlying oxygen diffusion zone is clearly also 

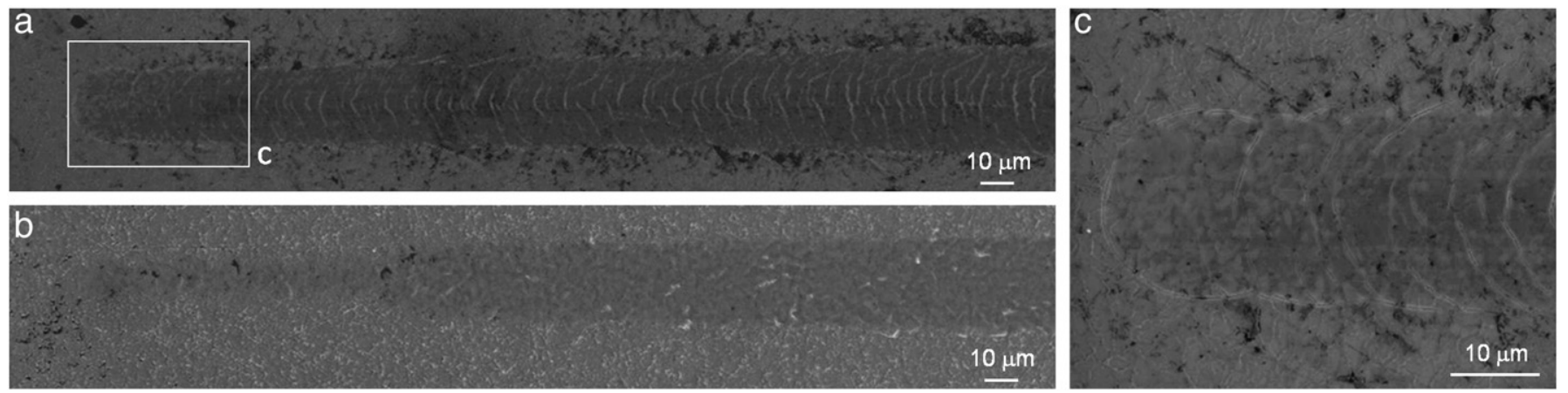

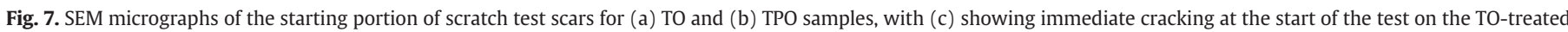
sample in (a).

very important as it reduces interfacial strain under the indenteravoiding premature failure. Indeed the resultant critical loads measured for TPO-treated surfaces approach values which are typically considered to be acceptable for PVD hard coatings deposited onto tool steel substrates $[42,43]$. This is of particular relevance when considering other reports, such as in [12,21], where the oxide layer adhesion reduces almost to zero as the thermal processing temperature reaches $700{ }^{\circ} \mathrm{C}$.

\subsection{Reciprocating-sliding wear testing}

The good adhesion strength observed during scratch tests should translate into an overall improvement in tribological performance. The wear behaviour of several of these oxidised samples was examined under reciprocating-sliding wear tests. The results of ball-on-plate wear testing (conducted using a WC-Co ball counterface) are shown in Fig. 8. It is evident that the TPO treatment suppressed the extensive wear which occurs in untreated Ti-alloy to much larger sliding distances.

The effectiveness of oxidising treatments was found to be superior to triode plasma nitrided (TPN) samples, in terms of frictional behaviouras discussed at length in [26]. Whilst the best performing nitrided samples survived to a distance of around $200 \mathrm{~m}$, TPO-treated samples discussed here survived more than $800 \mathrm{~m}$ under the same testing conditions. The reason for this is twofold; (i) a higher surface hardness for the TPO-treated sample $\left(\sim 1200 \mathrm{HK}_{0.025}\right.$ compared to $\sim 1050 \mathrm{HK}_{0.025}$ for TPN-treated), augmented by a thicker compound layer ( $1.88 \mu \mathrm{m}$ compared to $0.25 \mu \mathrm{m}$ for the nitride compound layer

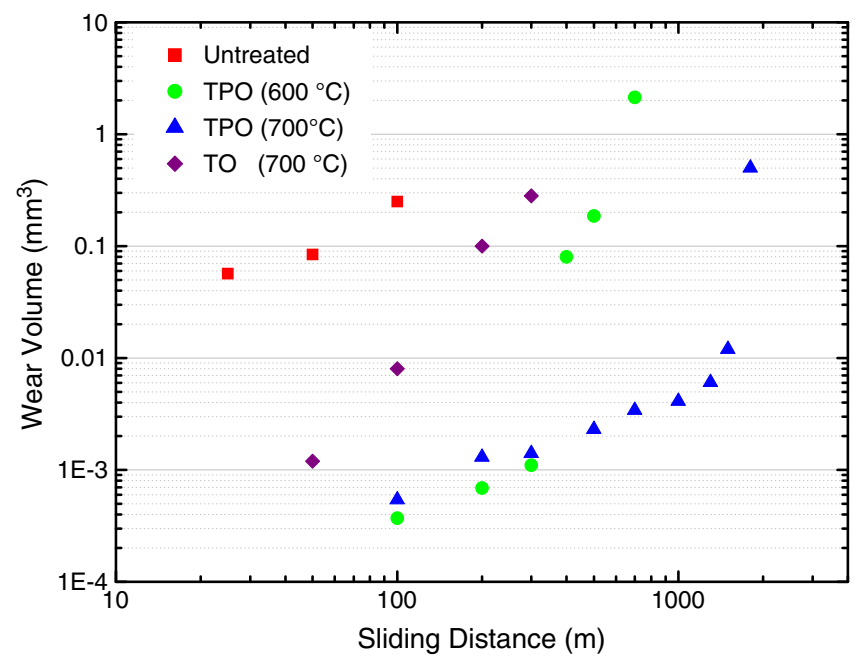

Fig. 8. Measured wear volumes for reciprocating-sliding tests on untreated and oxidised Ti-6Al-4V samples oxidised at different temperatures for $4 \mathrm{~h}$ and tested against WC-Co at $4 \mathrm{~N}$ load. TPO processes were carried out using a 30:70 $\mathrm{Ar}: \mathrm{O}_{2}$ partial pressure ratio. in an equivalent TPN treatment) but, more importantly, (ii) a significantly deeper hardening response in TPO (compared to TPN at the same treatment time/temperature). This relates primarily to differences in diffusion coefficients between the two elements. Although the 'bulk' diffusion coefficients of oxygen and nitrogen through $\alpha$-Ti are comparable at the temperatures used for this work [35,44], there exists a significant difference between the coefficients of diffusion of oxygen in $\mathrm{TiO}_{2}$, and nitrogen in TiN, of nearly 4 orders of magnitudein favour of oxygen. The direct consequence of this difference is the change in hardness-depth profiles noted for Ti-6Al-4V treated with either oxygen or nitrogen. This facilitates a contact with the counterface material which is (in the case of oxidised surfaces) predominantly elastic-since the deeper underlying diffusion-hardened zone inhibits any substantial surface plastic deformation under load.

As might be expected, an increase in processing temperature improves the tribological behaviour of oxygen diffusion-treated Ti-alloy. This is because of (i) the increase in surface hardness due to the formation of a thicker $(1.88 \mu \mathrm{m})$ oxide layer at $700{ }^{\circ} \mathrm{C}$ compared to only a thin interference layer of approximately $0.35 \mu \mathrm{m}$ at $600{ }^{\circ} \mathrm{C}$ and (ii) the deeper oxygen diffusion zone created by the accelerated diffusion kinetics at the higher temperatures. The resultant sliding distance to failure in samples TPO-treated at $600{ }^{\circ} \mathrm{C}$ is around $400 \mathrm{~m}$, whilst this approaches $1600 \mathrm{~m}$ (i.e. a four-fold increase) following treatment for the same time at $700{ }^{\circ} \mathrm{C}$. As opposed to the extensive galling and ploughing seen in the untreated substrate material, TPO treated samples wear progressively as the oxide layer is gradually broken down. No flaking or spalling was observed during testing of any of the TPO samples. This is in

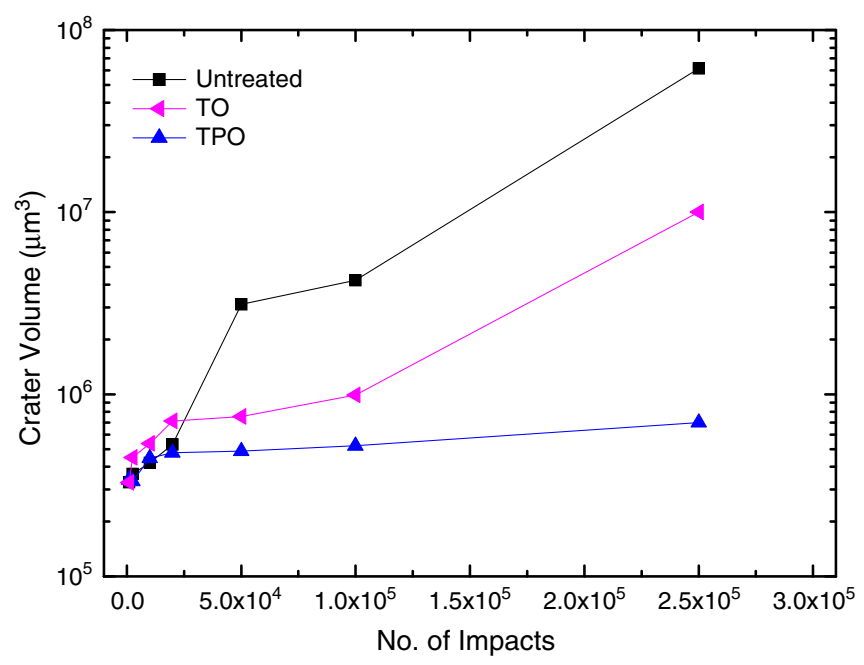

Fig. 9. Indentation volumes obtained from impact tests (400 N load) of untreated and oxidised Ti-6Al-4V samples, treated at $700{ }^{\circ} \mathrm{C}$ for $4 \mathrm{~h}$ (with TPO performed at 30:70 $\mathrm{Ar}: \mathrm{O}_{2}$ partial pressure ratio). 

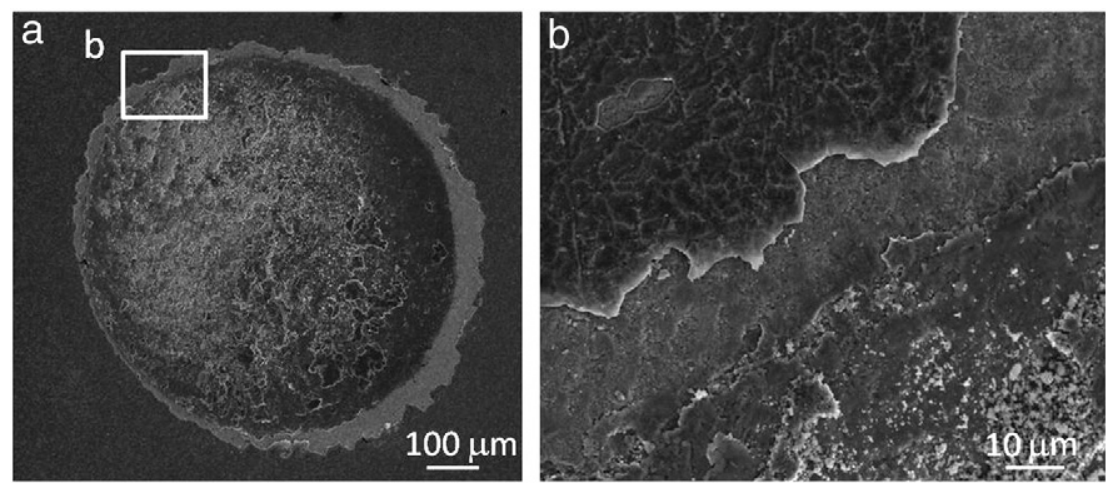

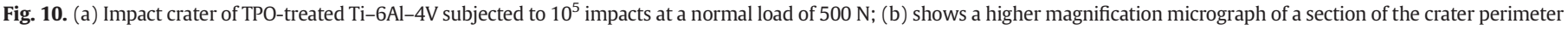
where the oxide compound layer has delaminated from the substrate.

agreement with the scratch test results and reflects the excellent cohesive and adhesive strength between the oxide layer and the oxygen-rich underlying substrate material.

These results were also compared to an equivalent thermal oxidation treatment. Fig. 8 shows the wear test results of an equally long $4 \mathrm{~h}$ TO process. The TO process is unable to provide adequate protection against wear beyond $100 \mathrm{~m}$ of sliding distance under the chosen loading conditions. Although prolonged treatment durations and/or higher temperatures may degrade the oxide layer quality [22] and therefore further reduce TO treatment efficacy, it is also clear that, for a thermal process, such a short treatment duration at $700{ }^{\circ} \mathrm{C}$ is insufficient for most engineering applications. This difference in performance between the two treatments is clearly related to the change in oxidation kinetics under triode plasma conditions.

Another interesting observation is that a TPO sample treated at $700{ }^{\circ} \mathrm{C}$ exhibits an equivalent wear resistance to duplex TPN + PVD TiN-coated samples (also discussed in [26]), when tested under a $4 \mathrm{~N}$ normal load. The higher diffusion coefficient of oxygen through the growing compound layer (as opposed to nitrogen through titanium nitride) provides superior load support to the (relatively thick) oxide layer formed. However, reciprocating-sliding wear tests held at $13.5 \mathrm{~N}$ show that, at higher contact pressures (which can in this case exceed the yield strength of the base metal), duplex TPN/TiN still significantly outperforms TPO-treated Ti-6Al-4V. Compared to the survival distance of the duplex TPN/TiN (around $250 \mathrm{~m}$ ), the TPO samples are unable to exceed $100 \mathrm{~m}$ of sliding before accelerated and catastrophic wear occurs. Clearly, given appropriate load-

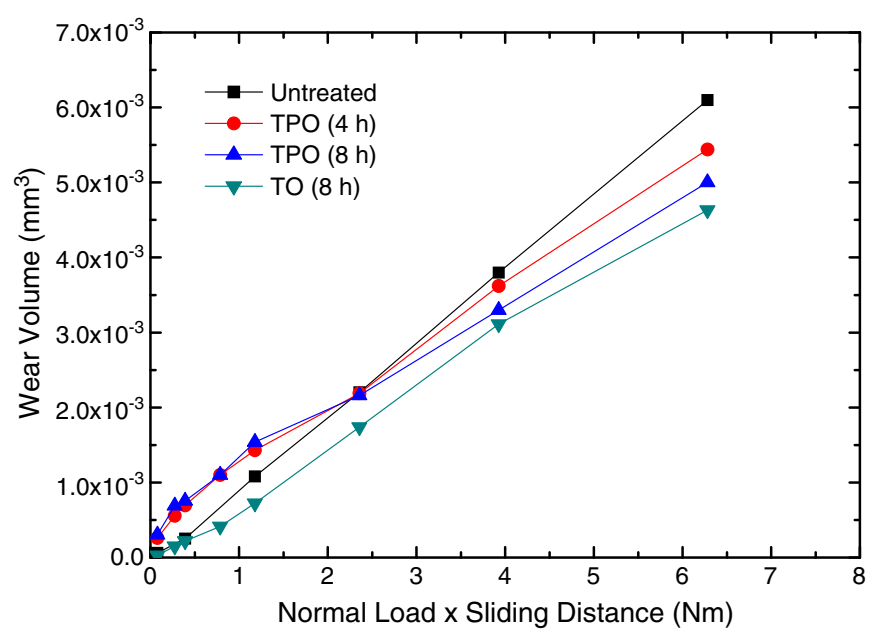

Fig. 11. Plot of $W S$ vs $V$ for untreated Ti-6Al-4V and oxidised at $700{ }^{\circ} \mathrm{C}$. TPO processes were carried out using a 30:70 $\mathrm{Ar}: \mathrm{O}_{2}$ partial pressure ratio. support, a harder (PVD) surface coating can still provide superior results at higher contact pressures.

\subsection{Impact wear testing}

The scratch test results presented in Section 3.1 imply that the oxide compound layer produced during triode plasma oxidation treatments can be dense, coherent and well adhered. This, together with the comparatively deep case provided by oxygen diffusion, should also provide superior surface fatigue strength under dynamic, high-cycle loadingand in turn good impact wear resistance. Indeed, impact testing of TPO-treated samples at $400 \mathrm{~N}$ normal load demonstrates that the crater volumes generated are much smaller than their equivalent on untreated material (Fig. 9). Samples TPO-treated at $700{ }^{\circ} \mathrm{C}$ for $4 \mathrm{~h}$ exhibit a noticeable increase in dynamic impact wear resistance, such that-between $20 \times 10^{3}$ and $250 \times 10^{3}$ impacts-there is almost negligible increase in the wear volume measured. The surface remains virtually intact, with no apparent cohesive and adhesive damage up to $250 \times 10^{3}$ impacts. Conversely, TO-treated samples exhibit an initial high wear rate, higher than that of the untreated substrate-due to the almost immediate delamination of the oxide layer. Then the wear crater volumes reduce, as the benefit of the oxygen-diffusion strengthening zone becomes apparent. Furthermore, these TO-treated samples, exhibit peripheral circular cracking of the compound layer, which forms almost immediately around the crater and progressively increases towards the centre of the wear scar, subsequently leading to substrate exposure-and a rapid increase in wear rate.

Once again, the TPO-treated sample behaviour can be compared and contrasted to equivalent TPN-treated samples, as discussed in [28]. The oxidation treatment is not only able to drastically reduce the wear rate but is in fact superior to all similar nitrogen-diffusion treatments performed at $700{ }^{\circ} \mathrm{C}$, when tested under a normal impact load of $400 \mathrm{~N}$. However, in order to observe whether such trends persisted at higher contact stress, further testing was carried out at $500 \mathrm{~N}$ for $100 \times 10^{3}$ impacts. At this load, the TPO sample fared much differently; the measured crater volume was as large as that of untreated Ti-6Al-4V and adhesive failure of the oxide layer was observed around the crater, outside the area of direct contact with the ball (Fig. 10).

Table 2

Wear coefficients of Ti surfaces subjected to various diffusion treatments.

\begin{tabular}{lcc}
\hline Sample & Wear coefficient $\left(\times 10^{-4} \mathrm{~mm}^{3} / \mathrm{N} \mathrm{m}\right)$ & $\Delta \kappa, \%$ (compared to untreated) \\
\hline Untreated & 9.65 & $/$ \\
TPO $(4 \mathrm{~h})$ & 8.28 & -14.2 \\
TPO $(8 \mathrm{~h})$ & 8.03 & -16.8 \\
TO $(8 \mathrm{~h})$ & 7.66 & -20.6 \\
\hline
\end{tabular}




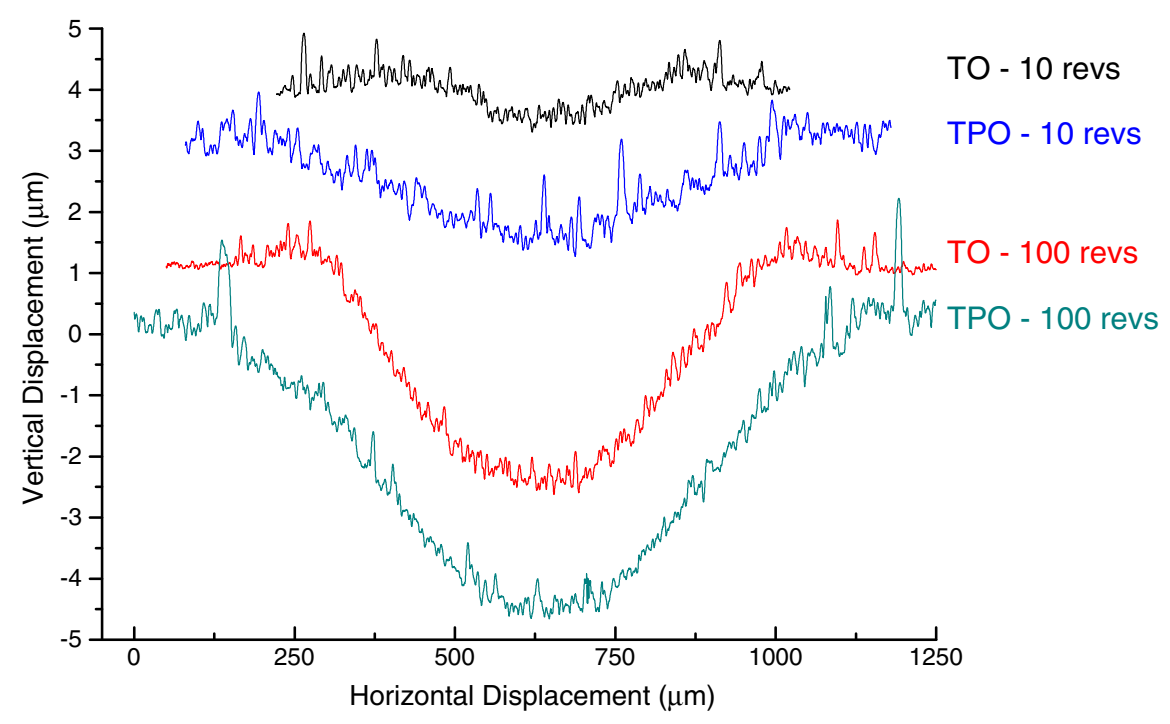

Fig. 12. 2D depth profiles of micro-abrasion wear scar cross-sections for $4 \mathrm{~h}$ thermal- and plasma-oxidation processes, measured after 10 and 100 ball revolutions.

\subsection{Micro-abrasion testing}

Abrasion wear coefficients for untreated and oxygen-treated $\mathrm{Ti}$ alloy were obtained from fitting lines to a plot of the product of the normal load $(W)$ and the sliding distance $(S), W S$ vs. the wear volume, $V$ (Fig. 11). The gradients of the linear regression lines (not shown) are tabulated in Table 2, together with the percentage change in micro-abrasion wear coefficient.

All oxygen-treated Ti-6Al-4V samples showed some degree of improvement-indicated as negative percentile changes in Table 2. However, closer examination of the data plots shown in Fig. 11 reveals an initially higher wear rate for 10,35 and 50 ball revolutions (equivalent to $0.08,0.27$ and $0.39 \mathrm{~N}$ m respectively) compared to the untreated material, for TPO-treated samples (but not in the case of the thermally oxidised sample). This was unexpected since, as previously highlighted, the TO process leads to a smaller increase in surface hardness when compared to plasma oxidation processes. However, this apparent superiority ceased when the wear scar reached around 1 to $2 \mu \mathrm{m}$ in depth. It is believed that this initial lower wear coefficient is due to the lower surface roughness of the TO treatment. In fact, the TO sample had an $R_{a}$ value of only $0.06 \mu \mathrm{m}$ i.e. only marginally higher than the untreated material. The higher $R_{a}$ values measured for TPO-treated samples $\left(R_{a} \sim 0.12 \mu \mathrm{m}\right)$ may increase the instantaneous wear coefficient at the beginning of the test by reducing the real contact area, thereby increasing the local contact stresses. The roughness of these samples eventually decreases and the gradient of the WS vs. $V$ plot lowers further-indicating a much lower 'steady-state' wear coefficient for TPO. Fig. 12 shows how initially the micro-abrasion scar of the rougher TPO sample is visibly more jagged-leading to a non-uniform pressure distribution inside the groove. However, as the test proceeds to longer sliding distances, the surface asperities are removed, leaving a notionally identical topography of both samples.

\section{Conclusions}

In this study, the thermal- and plasma-oxidation behaviour of Ti$6 \mathrm{Al}-4 \mathrm{~V}$ (and resultant tribological behaviour) was investigated. GA$\mathrm{XRD}$ analysis shows that rutile- and anatase-containing $\mathrm{TiO}_{2}$ compound layers were detected for all oxidised samples. Comparing TPO treatments to conventional thermal oxidation shows that, for identical process duration and temperature, the thermal process generates comparatively little oxide formation-revealing its inefficiency in promoting oxygen uptake. The results shown here demonstrate that triode plasma oxidation treatments provide Ti-6Al-4V with a hard and well-adhered surface compound layer on top of an oxygen-diffusion strengthened region which reaches down to $70 \mu \mathrm{m}$ below the sample surface.

Scratch adhesion testing of oxidised sample compound layers showed that oxide films generated by TPO processing have superior adhesion strength and improved mechanical properties compared to traditional thermal oxidation, making the former treatment a potential candidate for use in tribological applications.

In fact, TPO-treated samples show a large increase in wear resistance compared to the untreated alloy, when subjected to moderately high contact pressures under a range of different wear test regimes. Reciprocating-sliding, dynamic impact and micro-abrasion wear testing all showed significant reduction in wear rate following TPO treatment. In most cases, the improvements obtained are superior both to an equivalent thermal oxidation treatment and to triode plasma nitriding (TPN) processes.

Considering the relatively short timescale (and low treatment temperature) needed for effective TPO processing, this novel treatment shows significant potential as a cost-effective, single-step process for commercial Ti-alloy wear protection, capable of providing significant improvements in tribological performance. Such enhanced-plasma oxidation treatments may be a particularly attractive solution for mid-range performance at moderate contact pressures-and of interest for many tribological applications when the component geometry is relatively uncomplicated-permitting uniform plasma sheath distributions during processing.

\section{Acknowledgements}

The authors gratefully acknowledge financial support for several aspects of this research work from the UK Technology Strategy Board under Technology Programme project TP/22076, in collaboration with Tecvac Ltd., NMB-Minebea UK Ltd., and Airbus UK.

\section{References}

[1] G. Bertrand, K. Jarray, J.M. Chaiz, Oxid. Met. 21 (1983) 1045.

[2] C. Xu, W. Gao, Mater. Res. Innovations 3 (2000) 231.

[3] G.P. Burns, J. Appl. Phys. 65 (5) (1989) 2095.

[4] K.V. Krishna Rao, S.V. Nagender Naidu, L. lyengar, J. Am. Ceram. Soc. 53 (3) (1970) 124

[5] P.K. Imbrie, D.C. Lagouds, Oxid. Met. 55 (3/4) (2001) 359.

[6] A.K. Sharma, Thin Solid Films 208 (1992) 48.

[7] Y.X. Leng, J.Y. Chen, P. Yang, J. Wang, A.S. Zhao, G.J. Wan, H. Sun, N. Huang, Surf. Coat. Technol. 201 (2006) 1012.

[8] Y.X. Leng, J.Y. Chen, P. Yang, H. Sun, N. Huang, Surf. Coat. Technol. 166 (2003) 176 
[9] A.L. Yerokhin, X. Nie, A. Leyland, A. Matthews, Surf. Coat. Technol. 130 (2000) 195.

[10] T. Sonoda, M. Kato, Thin Solid Films 303 (1997) 196.

[11] V.M. Fedirko, A.T. Pichuhin, O.H. Lukyanenko, V.S. Onuferko, Mater. Sci. 41 (2) (2005) 208.

[12] H. Guleryin, H. Cimenoglu, Surf. Coat. Technol. 192 (2005) 164.

[13] C. Boettcher, T. Bell, H. Dong, Metall. Trans. A 33A (2002) 1201.

[14] H. Dong, X.Y. Li, Mater. Sci. Eng. A-Struct. 280 (2000) 303.

[15] C. Boettcher, Surf. Eng. 16 (2) (2000) 148.

[16] C. Hertl, E. Werner, R. Thull, U. Gbureck, Biomed. Mater. 5 (2010) 1.

[17] H. Dong, T. Bell, Ind. Lubr. Tribol. 50 (6) (1998) 282.

[18] A. Bloyce, P.-Y. Qi, H. Dong, T. Bell, Surf. Coat. Technol. 107 (1998) 125.

[19] H. Dong, T. Bell, Wear 238 (2000) 131.

[20] D. Siva Rama Krishna, Y.L. Brama, Y. Sun, Tribol. Int. 40 (2007) 329.

[21] C. Coddet, A.M. Chaze, G. Beranger, J. Mater. Sci. 22 (1987) 2969

[22] H. Dong, A. Bloyce, P.H. Morton, T. Bell, Surf. Eng. 13 (5) (1997) 402

[23] F. Borgioli, E. Galvanetto, F. Iozzelli, G. Pradelli, Mater. Lett. 59 (2005) 2159.

[24] W. Yan, X.X. Wang, J. Mater. Sci. Lett. 39 (2004) 5583.

25] B. Januszewicz, D. Siniarski, Vacuum 81 (2006) 215.

[26] G. Cassar, J.C. Avelar-Batista Wilson, S. Banfield, J. Housden, A. Matthews, A. Leyland, Wear 269 (2010) 60.

[27] G. Cassar, S. Banfield, J.C. Avelar-Batista Wilson, J. Housden, A. Matthews, A Leyland, Surf. Coat. Technol. 206 (2011) 395.

[28] G. Cassar, S. Banfield, J.C. Avelar-Batista Wilson, J. Housden, A. Matthews, A. Leyland, Surf. Coat. Technol. 206 (2012) 2645.

[29] G. Cassar, S. Banfield, J.C. Avelar-Batista Wilson, J. Housden, A. Matthews, A. Leyland Wear 274-275 (2012) 377.
[30] S. Banfield, J.C. Avelar-BatistaWilson, G. Cassar, A. Leyland, A. Matthews, J. Housden, Surf. Coat. Technol. 206 (2011) 1955.

[31] A. Leyland, K.S. Fancey, A. Matthews, Surf. Eng. 7 (3) (1991) 207.

[32] A. Leyland, K.S. Fancey, A.S. James, A. Matthews, Surf. Coat. Technol. 41 (1990) 295.

[33] G133-05e1, Standard Test Method for Linearly Reciprocating Ball-on-flat Sliding Wear, ASTM International, 2005, p. 1.

[34] R. Bantle, A. Matthews, Surf. Coat. Technol. 74-75 (1995) 857.

[35] J. Unnam, R.N. Shenoy, R.K. Clark, Oxid. Met. 26 (3/4) (1986) 231.

[36] S. Rao, T. Ushida, T. Tateishi, Y. Okazaki, S. Asao, Bio-Med. Mater. Eng. 6 (2) (1996) 79.

[37] S. Yumoto, H. Nagai, M. Imamura, H. Matsuzaki, K. Hayashi, A. Masuda, H. Kumazawa, H. Ohashi, K. Kobayashi, Nucl. Instrum. Methods B 123 (1997) 279.

[38] S. Yamaguchi, J. Phys. Soc. Jpn. 27 (1) (1969) 155.

[39] C. Leyens, M. Peters (Eds.), Titanium and Titanium Alloys: Fundamentals and Applications, Wiley-VCH, 2005, p. 6, 210.

[40] F. Borgioli, E. Galvanetto, F.P. Galliano, T. Bacci, Surf. Coat. Technol. 141 (2001) 103.

[41] F. Borgioli, E. Galvanetto, A. Fossati, G. Pradelli, Surf. Coat. Technol. 184 (2004) 255.

[42] F. Bunshah (Ed.), Handbook of Hard Coatings; Deposition Technologies, Properties and Applications, William Andrew, New York, 2001, p. 521.

[43] O. Wanstrand, M. Larsson, P. Hedenqvist, Surf. Coat. Technol. 111 (1999) 247.

[44] E. Metin, O.T. Inal, Metall. Trans. A 20(A) (1989) 1819. 